\title{
Existence and Strong Convergence Theorems for Generalized Mixed Equilibrium Problems of a Finite Family of Asymptotically Nonexpansive Mappings in Banach Spaces
}

\author{
Rabian Wangkeeree, ${ }^{1,2}$ Hossein Dehghan, ${ }^{3}$ \\ and Pakkapon Preechasilp ${ }^{1}$ \\ ${ }^{1}$ Department of Mathematics, Faculty of Science, Naresuan University, Phitsanulok 65000, Thailand \\ ${ }^{2}$ Centre of Excellence in Mathematics, CHE, Si Ayutthaya Road, Bangkok 10400, Thailand \\ ${ }^{3}$ Department of Mathematics, Institute for Advanced Studies in Basic Sciences (IASBS), Gava Zang, \\ Zanjan 45137-66731, Iran
}

Correspondence should be addressed to Rabian Wangkeeree, rabianw@nu.ac.th

Received 5 April 2012; Accepted 10 May 2012

Academic Editor: Giuseppe Marino

Copyright (C) 2012 Rabian Wangkeeree et al. This is an open access article distributed under the Creative Commons Attribution License, which permits unrestricted use, distribution, and reproduction in any medium, provided the original work is properly cited.

\begin{abstract}
We first prove the existence of solutions for a generalized mixed equilibrium problem under the new conditions imposed on the given bifunction and introduce the algorithm for solving a common element in the solution set of a generalized mixed equilibrium problem and the common fixed point set of finite family of asymptotically nonexpansive mappings. Next, the strong convergence theorems are obtained, under some appropriate conditions, in uniformly convex and smooth Banach spaces. The main results extend various results existing in the current literature.
\end{abstract}

\section{Introduction}

Let $E$ be a real Banach space with the dual $E^{*}$ and $C$ be a nonempty closed convex subset of $E$. We denote by $\mathbb{N}$ and $\mathbb{R}$ the sets of positive integers and real numbers, respectively. Also, we denote by $J$ the normalized duality mapping from $E$ to $2^{E^{*}}$ defined by

$$
J x=\left\{x^{*} \in E^{*}:\left\langle x, x^{*}\right\rangle=\|x\|^{2}=\left\|x^{*}\right\|^{2}\right\}, \quad \forall x \in E,
$$

where $\langle\cdot, \cdot\rangle$ denotes the generalized duality pairing. Recall that if $E$ is smooth, then $J$ is single valued and if $E$ is uniformly smooth, then $J$ is uniformly norm-to-norm continuous on bounded subsets of $E$. We will still denote by $J$ the single-valued duality mapping. 
A mapping $S: C \rightarrow E$ is called nonexpansive if $\|S x-S y\| \leq\|x-y\|$ for all $x, y \in C$. Also a mapping $S: C \rightarrow C$ is called asymptotically nonexpansive if there exists a sequence $\left\{k_{n}\right\} \subset$ $[1, \infty)$ with $k_{n} \rightarrow 1$ as $n \rightarrow \infty$ such that $\left\|S^{n} x-S^{n} y\right\| \leq k_{n}\|x-y\|$ for all $x, y \in C$ and for each $n \geq 1$. Denote by $F(S)$ the set of fixed points of $S$, that is, $F(S)=\{x \in C: S x=x\}$. The following example shows that the class of asymptotically nonexpansive mappings which was first introduced by Goebel and Kirk [1] is wider than the class of nonexpansive mappings.

Example 1.1 (see [2]). Let $B_{H}$ be the closed unit ball in the Hilbert space $H=l_{2}$ and $S: B_{H} \rightarrow$ $B_{H}$ a mapping defined by

$$
S\left(x_{1}, x_{2}, x_{3}, \ldots\right)=\left(0, x_{1}^{2}, a_{2} x_{2}, a_{3} x_{3}, \ldots\right)
$$

where $\left\{a_{n}\right\}$ is a sequence of real numbers such that $0<a_{i}<1$ and $\prod_{i=2}^{\infty} a_{i}=1 / 2$. Then

$$
\|S x-S y\| \leq 2\|x-y\|, \quad \forall x, y \in B_{H} .
$$

That is, $S$ is Lipschitzian but not nonexpansive. Observe that

$$
\left\|S^{n} x-S^{n} y\right\| \leq 2 \prod_{i=2}^{n} a_{i}\|x-y\|, \quad \forall x, y \in B_{H}, n \geq 2
$$

Here $k_{n}=2 \prod_{i=2}^{n} a_{i} \rightarrow 1$ as $n \rightarrow \infty$. Therefore, $S$ is asymptotically nonexpansive but not nonexpansive.

A mapping $T: C \rightarrow E^{*}$ is said to be relaxed $\eta-\xi$ monotone if there exist a mapping $\eta: C \times C \rightarrow E$ and a function $\xi: E \rightarrow \mathbb{R}$ positively homogeneous of degree $p$, that is, $\xi(t z)=t^{p} \xi(z)$ for all $t>0$ and $z \in E$ such that

$$
\langle T x-T y, \eta(x, y)\rangle \geq \xi(x-y), \quad \forall x, y \in C,
$$

where $p>1$ is a constant; see [3]. In the case of $\eta(x, y)=x-y$ for all $x, y \in C, T$ is said to be relaxed $\xi$-monotone. In the case of $\eta(x, y)=x-y$ for all $x, y \in C$ and $\xi(z)=k\|z\|^{p}$, where $p>1$ and $k>0, T$ is said to be $p$-monotone; see [4-6]. In fact, in this case, if $p=2$, then $T$ is a $k$-strongly monotone mapping. Moreover, every monotone mapping is relaxed $\eta-\xi$ monotone with $\eta(x, y)=x-y$ for all $x, y \in C$ and $\xi=0$. The following is an example of $\eta-\xi$ monotone mapping which can be found in [3]. Let $C=(-\infty, \infty), T x=-x$, and

$$
\eta(x, y)= \begin{cases}-c(x-y), & x \geq y \\ c(x-y), & x<y\end{cases}
$$

where $c>0$ is a constant. Then, $T$ is relaxed $\eta-\xi$ monotone with

$$
\xi(z)= \begin{cases}c z^{2}, & z \geq 0 \\ -c z^{2}, & z<0\end{cases}
$$


A mapping $T: C \rightarrow E^{*}$ is said to be $\eta$-hemicontinuous if, for each fixed $x, y \in C$, the mapping $f:[0,1] \rightarrow(-\infty,+\infty)$ defined by $f(t)=\langle T(x+t(y-x)), \eta(y, x)\rangle$ is continuous at $0^{+}$. For a real Banach space $E$ with the dual $E^{*}$ and for $C$ a nonempty closed convex subset of $E$, let $f: C \times C \rightarrow \mathbb{R}$ be a bifunction, $\varphi: C \rightarrow \mathbb{R}$ a real-valued function and $T: C \rightarrow E^{*}$ be a relaxed $\eta-\xi$ monotone mapping. Recently, Kamraksa and Wangkeeree [7] introduced the following generalized mixed equilibrium problem (GMEP).

Find $x \in C$ such that $f(x, y)+\langle T x, \eta(y, x)\rangle+\varphi(y) \geq \varphi(x), \quad \forall y \in C$.

The set of such $x \in C$ is denoted by $\operatorname{GMEP}(f, T)$, that is,

$$
\operatorname{GMEP}(f, T)=\{x \in C: f(x, y)+\langle T x, \eta(y, x)\rangle+\varphi(y) \geq \varphi(x), \forall y \in C\}
$$

\section{Special Cases}

(1) If $T$ is monotone that is $T$ is relaxed $\eta-\xi$ monotone with $\eta(x, y)=x-y$ for all $x, y \in C$ and $\xi=0$, (1.8) is reduced to the following generalized equilibrium problem (GEP).

$$
\text { Find } x \in C \text { such that } f(x, y)+\langle T x, y-x\rangle+\varphi(y) \geq \varphi(x), \quad \forall y \in C \text {. }
$$

The solution set of (1.10) is denoted by $\operatorname{GEP}(f)$, that is,

$$
\operatorname{GEP}(f)=\{x \in C: f(x, y)+\langle T x, y-x\rangle+\varphi(y) \geq \varphi(x), \forall y \in C\}
$$

(2) In the case of $T \equiv 0$ and $\varphi \equiv 0,(1.8)$ is reduced to the following classical equilibrium problem

$$
\text { Find } x \in C \text { such that } f(x, y) \geq 0, \quad \forall y \in C \text {. }
$$

The set of all solution of (1.12) is denoted by $\mathrm{EP}(f)$, that is,

$$
\operatorname{EP}(f)=\{x \in C: f(x, y) \geq 0, \forall y \in C\} .
$$

(3) In the case of $f \equiv 0,(1.8)$ is reduced to the following variational-like inequality problem [3].

Find $x \in C$ such that $\langle T x, \eta(y, x)\rangle+\varphi(y)-\varphi(x) \geq 0, \quad \forall y \in C$.

The generalized mixed equilibrium problem (GMEP) (1.8) is very general in the sense that it includes, as special cases, optimization problems, variational inequalities, minimax problems, and Nash equilibrium problems. Using the KKM technique introduced by Kanster et al. [8] and $\eta-\xi$ monotonicity of the mapping $\varphi$, Kamraksa and Wangkeeree [7] obtained the existence of solutions of generalized mixed equilibrium problem (1.8) in a real reflexive Banach space. 
Some methods have been proposed to solve the equilibrium problem in a Hilbert space; see, for instance, Blum and Oettli [9], Combettes and Hirstoaga [10], and Moudafi [11]. On the other hand, there are several methods for approximation fixed points of a nonexpansive mapping; see, for instance, [12-17]. Recently, Tada and Takahashi $[13,16]$ and S. Takahashi and W. Takahashi [17] obtained weak and strong convergence theorems for finding a common elements in the solution set of an equilibrium problem and the set of fixed point of a nonexpansive mapping in a Hilbert space. In particular, Tada and Takahashi [16] established a strong convergence theorem for finding a common element of two sets by using the hybrid method introduced in Nakajo and Takahashi [18]. They also proved such a strong convergence theorem in a uniformly convex and uniformly smooth Banach space.

On the other hand, in 1953, Mann [12] introduced the following iterative procedure to approximate a fixed point of a nonexpansive mapping $S$ in a Hilbert space $H$ :

$$
x_{n+1}=\alpha_{n} x_{n}+\left(1-\alpha_{n}\right) S x_{n}, \quad \forall n \in \mathbb{N},
$$

where the initial point $x_{0}$ is taken in $C$ arbitrarily and $\left\{\alpha_{n}\right\}$ is a sequence in $[0,1]$. However, we note that Manns iteration process (1.15) has only weak convergence, in general; for instance, see [19-21]. In 2003, Nakajo and Takahashi [18] proposed the following sequence for a nonexpansive mapping $S$ in a Hilbert space:

$$
\begin{gathered}
x_{0}=x \in C, \\
y_{n}=\alpha_{n} x_{n}+\left(1-\alpha_{n}\right) S x_{n}, \\
C_{n}=\left\{z \in C:\left\|y_{n}-z\right\| \leq\left\|x_{n}-z\right\|\right\}, \\
Q_{n}=\left\{z \in C:\left\langle x_{n}-z, x_{0}-x_{n}\right\rangle \geq 0\right\}, \\
x_{n+1}=P_{C_{n} \cap Q_{n}} x_{0},
\end{gathered}
$$

where $0 \leq \alpha_{n} \leq a<1$ for all $n \in \mathbb{N}$, and $P_{C_{n} \cap D_{n}}$ is the metric projection from $E$ onto $C_{n} \cap D_{n}$. Then, they proved that $\left\{x_{n}\right\}$ converges strongly to $P_{F(T)} x_{0}$. Recently, motivated by Nakajo and Takahashi [18] and Xu [22], Matsushita and Takahashi [14] introduced the iterative algorithm for finding fixed points of nonexpansive mappings in a uniformly convex and smooth Banach space: $x_{0}=x \in C$ and

$$
\begin{gathered}
C_{n}=\overline{\mathrm{co}}\left\{z \in C:\|z-S z\| \leq t_{n}\left\|x_{n}-S x_{n}\right\|\right\}, \\
D_{n}=\left\{z \in C:\left\langle x_{n}-z, J\left(x-x_{n}\right)\right\rangle \geq 0\right\}, \\
x_{n+1}=P_{C_{n} \cap D_{n}} x, \quad n \geq 0,
\end{gathered}
$$

where $\overline{\mathrm{co}} D$ denotes the convex closure of the set $D,\left\{t_{n}\right\}$ is a sequence in $(0,1)$ with $t_{n} \rightarrow 0$. They proved that $\left\{x_{n}\right\}$ generated by (1.17) converges strongly to a fixed point of $S$. Very recently, Dehghan [23] investigated iterative schemes for finding fixed point of an asymptotically nonexpansive mapping and proved strong convergence theorems in a 
uniformly convex and smooth Banach space. More precisely, he proposed the following algorithm: $x_{1}=x \in C, C_{0}=D_{0}=C$ and

$$
\begin{gathered}
C_{n}=\overline{\mathrm{co}}\left\{z \in C_{n-1}:\left\|z-S^{n} z\right\| \leq t_{n}\left\|x_{n}-S^{n} x_{n}\right\|\right\}, \\
D_{n}=\left\{z \in D_{n-1}:\left\langle x_{n}-z, J\left(x-x_{n}\right)\right\rangle \geq 0\right\}, \\
x_{n+1}=P_{C_{n} \cap D_{n}} x, \quad n \geq 0,
\end{gathered}
$$

where $\left\{t_{n}\right\}$ is a sequence in $(0,1)$ with $t_{n} \rightarrow 0$ as $n \rightarrow \infty$ and $S$ is an asymptotically nonexpansive mapping. It is proved in [23] that $\left\{x_{n}\right\}$ converges strongly to a fixed point of $S$.

On the other hand, recently, Kamraksa and Wangkeeree [7] studied the hybrid projection algorithm for finding a common element in the solution set of the GMEP and the common fixed point set of a countable family of nonexpansive mappings in a uniformly convex and smooth Banach space.

Motivated by the above mentioned results and the on-going research, we first prove the existence results of solutions for GMEP under the new conditions imposed on the bifunction $f$. Next, we introduce the following iterative algorithm for finding a common element in the solution set of the GMEP and the common fixed point set of a finite family of asymptotically nonexpansive mappings $\left\{S_{1}, S_{2}, \ldots, S_{N}\right\}$ in a uniformly convex and smooth Banach space: $x_{0} \in C, D_{0}=C_{0}=C$, and

$$
\begin{gathered}
x_{1}=P_{C_{0} \cap D_{0}} x_{0}=P_{C} x_{0}, \\
C_{1}=\overline{\mathrm{co}}\left\{z \in C:\left\|z-S_{1} z\right\| \leq t_{1}\left\|x_{1}-S_{1} x_{1}\right\|\right\}, \\
u_{1} \in C \text { such that } f\left(u_{1}, y\right)+\varphi(y)+\left\langle T u_{1}, \eta\left(y, u_{1}\right)\right\rangle+\frac{1}{r_{1}}\left\langle y-u_{1}, J\left(u_{1}-x_{1}\right)\right\rangle, \quad \forall y \in C, \\
D_{1}=\left\{z \in C:\left\langle u_{1}-z, J\left(x_{1}-u_{1}\right)\right\rangle \geq 0\right\}, \\
x_{2}=P_{C_{1} \cap D_{1}} x_{0}, \\
\vdots \\
u_{N} \in C \text { such that } f\left(u_{N}, y\right)+\varphi(y)+\left\langle T u_{N}, \eta\left(y, u_{N}\right)\right\rangle+\frac{1}{r_{N}}\left\langle y-u_{N}, J\left(u_{N}-x_{N}\right)\right\rangle, \quad \forall y \in C, \\
D_{N}=\left\{z \in D_{N-1}:\left\langle u_{N}-z, J\left(x_{N}-u_{N}\right)\right\rangle \geq 0\right\}, \\
x_{N+1}=P_{C_{N} \cap D_{N}} x_{0}, \\
C_{N+1}=\overline{\mathrm{co}}\left\{z \in C_{N}:\left\|z-S_{1}^{2} z\right\| \leq t_{1}\left\|x_{N+1}-S_{1}^{2} x_{N+1}\right\|\right\}, \\
u_{N+1} \in C \text { such that } f\left(u_{N+1}, y\right)+\varphi(y)+\left\langle T u_{N+1}, \eta\left(y, u_{N+1}\right)\right\rangle \\
1 \\
+\frac{1}{r_{N+1}}\left\langle y-u_{N+1}, J\left(u_{N+1}-x_{N+1}\right)\right\rangle, \quad \forall y \in C,
\end{gathered}
$$




$$
\begin{gathered}
D_{N+1}=\left\{z \in D_{N}:\left\langle u_{N+1}-z, J\left(x_{N+1}-u_{N+1}\right)\right\rangle \geq 0\right\}, \\
x_{N+2}=P_{C_{N+1} \cap D_{N+1}} x_{0} \\
\vdots \\
C_{2 N}=\overline{c o}\left\{z \in C_{2 N-1}:\left\|z-S_{N}^{2} z\right\| \leq t_{1}\left\|x_{2 N}-S_{N}^{2} x_{2 N}\right\|\right\} \\
u_{2 N} \in C \text { such that } f\left(u_{2 N}, y\right)+\varphi(y)+\left\langle T u_{2 N}, \eta\left(y, u_{2 N}\right)\right\rangle \\
+\frac{1}{r_{2 N}}\left\langle y-u_{2 N}, J\left(u_{2 N}-x_{2 N}\right)\right\rangle, \quad \forall y \in C, \\
D_{2 N}=\left\{z \in D_{2 N-1}:\left\langle u_{2 N}-z, J\left(x_{2 N}-u_{2 N}\right)\right\rangle \geq 0\right\}, \\
x_{2 N+1}=P_{C_{2 N} \cap D_{2 N}} x_{0}, \\
C_{2 N+1}=\overline{c o}\left\{z \in C_{2 N}:\left\|z-S_{1}^{3} z\right\| \leq t_{1}\left\|x_{2 N+1}-S_{1}^{3} x_{2 N+1}\right\|\right\} \\
\in C \text { such that } f\left(u_{2 N+1}, y\right)+\varphi(y)+\left\langle T u_{2 N+1}, \eta\left(y, u_{2 N+1}\right)\right\rangle \\
+\frac{1}{r_{2 N+1}}\left\langle y-u_{2 N+1} J\left(u_{2 N+1}-x_{2 N+1}\right)\right\rangle, \quad \forall y \in C, \\
D_{2 N+1}=\left\{z \in D_{2 N}:\left\langle u_{2 N+1}-z, J\left(x_{2 N+1}-u_{2 N+1}\right)\right\rangle \geq 0\right\}, \\
x_{2 N+2}=P_{C_{2 N+1} \cap D_{2 N+1}} x_{0},
\end{gathered}
$$

The above algorithm is called the hybrid iterative algorithm for a finite family of asymptotically nonexpansive mappings from $C$ into itself. Since, for each $n \geq 1$, it can be written as $n=(h-1) N+i$, where $i=i(n) \in\{1,2, \ldots, N\}, h=h(n) \geq 1$ is a positive integer and $h(n) \rightarrow \infty$ as $n \rightarrow \infty$. Hence the above table can be written in the following form:

$$
\begin{gathered}
x_{0} \in C, \quad D_{0}=C_{0}=C, \\
C_{n}=\overline{\mathrm{co}}\left\{z \in C_{n-1}:\left\|z-S_{i(n)}^{h(n)} z\right\| \leq t_{n}\left\|x_{n}-S_{i(n)}^{h(n)} x_{n}\right\|\right\}, \quad n \geq 1, \\
u_{n} \in C \text { such that } f\left(u_{n}, y\right)+\varphi(y)+\left\langle T u_{n}, \eta\left(y, u_{n}\right)\right\rangle \\
+\frac{1}{r_{n}}\left\langle y-u_{n}, J\left(u_{n}-x_{n}\right)\right\rangle, \quad \forall y \in C, n \geq 1, \\
D_{n}=\left\{z \in D_{n-1}:\left\langle u_{n}-z, J\left(x_{n}-u_{n}\right)\right\rangle \geq 0\right\}, \quad n \geq 1, \\
x_{n+1}=P_{C_{n} \cap D_{n}} x_{0}, \quad n \geq 0 .
\end{gathered}
$$

Strong convergence theorems are obtained in a uniformly convex and smooth Banach space. The results presented in this paper extend and improve the corresponding Kimura and Nakajo [24], Kamraksa and Wangkeeree [7], Dehghan [23], and many others. 


\section{Preliminaries}

Let $E$ be a real Banach space and let $U=\{x \in E:\|x\|=1\}$ be the unit sphere of $E$. A Banach space $E$ is said to be strictly convex if for any $x, y \in U$,

$$
x \neq y \text { implies }\|x+y\|<2 .
$$

It is also said to be uniformly convex if for each $\varepsilon \in(0,2]$, there exists $\delta>0$ such that for any $x, y \in U$,

$$
\|x-y\| \geq \varepsilon \text { implies }\|x+y\|<2(1-\delta)
$$

It is known that a uniformly convex Banach space is reflexive and strictly convex. Define a function $\delta:[0,2] \rightarrow[0,1]$ called the modulus of convexity of $E$ as follows:

$$
\delta(\varepsilon)=\inf \left\{1-\left\|\frac{x+y}{2}\right\|: x, y \in E,\|x\|=\|y\|=1,\|x-y\| \geq \varepsilon\right\} .
$$

Then $E$ is uniformly convex if and only if $\delta(\varepsilon)>0$ for all $\varepsilon \in(0,2]$. A Banach space $E$ is said to be smooth if the limit

$$
\lim _{t \rightarrow 0} \frac{\|x+t y\|-\|x\|}{t}
$$

exists for all $x, y \in U$. Let $C$ be a nonempty, closed, and convex subset of a reflexive, strictly convex, and smooth Banach space $E$. Then for any $x \in E$, there exists a unique point $x_{0} \in C$ such that

$$
\left\|x_{0}-x\right\| \leq \min _{y \in C}\|y-x\|
$$

The mapping $P_{C}: E \rightarrow C$ defined by $P_{C} x=x_{0}$ is called the metric projection from $E$ onto $C$. Let $x \in E$ and $u \in C$. The following theorem is well known.

Theorem 2.1. Let $C$ be a nonempty convex subset of a smooth Banach space $E$ and let $x \in E$ and $y \in C$. Then the following are equivalent:

(a) $y$ is a best approximation to $x: y=P_{C} x$,

(b) $y$ is a solution of the variational inequality:

$$
\langle y-z, J(x-y)\rangle \geq 0 \quad \forall z \in C,
$$

where $J$ is a duality mapping and $P_{C}$ is the metric projection from $E$ onto $C$.

It is well known that if $P_{C}$ is a metric projection from a real Hilbert space $H$ onto a nonempty, closed, and convex subset $C$, then $P_{C}$ is nonexpansive. But, in a general Banach space, this fact is not true.

In the sequel one will need the following lemmas. 
Lemma 2.2 (see [25]). Let E be a uniformly convex Banach space, let $\left\{\alpha_{n}\right\}$ be a sequence of real numbers such that $0<b \leq \alpha_{n} \leq c<1$ for all $n \geq 1$, and let $\left\{x_{n}\right\}$ and $\left\{y_{n}\right\}$ be sequences in $E$ such that $\limsup _{n \rightarrow \infty}\left\|x_{n}\right\| \leq d$, $\limsup _{n \rightarrow \infty}\left\|y_{n}\right\| \leq d$ and $\lim _{n \rightarrow \infty}\left\|\alpha_{n} x_{n}+\left(1-\alpha_{n}\right) y_{n}\right\|=d$. Then $\lim _{n \rightarrow \infty}\left\|x_{n}-y_{n}\right\|=0$.

Dehghan [23] obtained the following useful result.

Theorem 2.3 (see [23]). Let $C$ be a bounded, closed, and convex subset of a uniformly convex Banach space $E$. Then there exists a strictly increasing, convex, and continuous function $\gamma:[0, \infty) \rightarrow[0, \infty)$ such that $r(0)=0$ and

$$
r\left(\frac{1}{k_{m}}\left\|S^{m}\left(\sum_{i=1}^{n} \lambda_{i} x_{i}\right)-\sum_{i=1}^{n} \lambda_{i} S^{m} x_{i}\right\|\right) \leq \max _{1 \leq j \leq k \leq n}\left(\left\|x_{j}-x_{k}\right\|-\frac{1}{k_{m}}\left\|S^{m} x_{j}-S^{m} x_{k}\right\|\right)
$$

for any asymptotically nonexpansive mapping $S$ of $C$ into $C$ with $\left\{k_{n}\right\}$, any elements $x_{1}, x_{2}, \ldots, x_{n} \in$ $C$, any numbers $\lambda_{1}, \lambda_{2}, \ldots, \lambda_{n} \geq 0$ with $\sum_{i=1}^{n} \lambda_{i}=1$ and each $m \geq 1$.

Lemma 2.4 (see [26, Lemma 1.6]). Let $E$ be a uniformly convex Banach space, $C$ be a nonempty closed convex subset of $E$ and $S: C \rightarrow C$ be an asymptotically nonexpansive mapping. Then $(I-S)$ is demiclosed at 0 , that is, if $x_{n} \rightarrow x$ and $(I-S) x_{n} \rightarrow 0$, then $x \in F(S)$.

The following lemma can be found in [7].

Lemma 2.5 (see [7, Lemma 3.2]). Let $C$ be a nonempty, bounded, closed, and convex subset of a smooth, strictly convex, and reflexive Banach space $E$, let $T: C \rightarrow E^{*}$ be an $\eta$-hemicontinuous and relaxed $\eta-\xi$ monotone mapping. Let $f$ be a bifunction from $C \times C$ to $R$ satisfying $(A 1),(A 3)$, and (A4) and let $\varphi$ be a lower semicontinuous and convex function from $C$ to $R$. Let $r>0$ and $z \in C$. Assume that

(i) $\eta(x, y)+\eta(y, x)=0$ for all $x, y \in C$;

(ii) for any fixed $u, v \in C$, the mapping $x \mapsto\langle T v, \eta(x, u)\rangle$ is convex and lower semicontinuous;

(iii) $\xi: E \rightarrow R$ is weakly lower semicontinuous, that is, for any net $\left\{x_{\beta}\right\}, x_{\beta}$ converges to $x$ in $\sigma\left(E, E^{*}\right)$ which implies that $\xi(x) \leq \liminf \xi\left(x_{\beta}\right)$.

Then there exists $x_{0} \in C$ such that

$$
f\left(x_{0}, y\right)+\left\langle T x_{0}, \eta\left(y, x_{0}\right)\right\rangle+\varphi(y)+\frac{1}{r}\left\langle y-x_{0}, J\left(x_{0}-z\right)\right\rangle \geq \varphi\left(x_{0}\right), \quad \forall y \in C
$$

Lemma 2.6 (see [7, Lemma 3.3]). Let $C$ be a nonempty, bounded, closed, and convex subset of a smooth, strictly convex, and reflexive Banach space $E$, let $T: C \rightarrow E^{*}$ be an $\eta$-hemicontinuous and relaxed $\eta-\xi$ monotone mapping. Let $f$ be a bifunction from $C \times C$ to $R$ satisfying (A1)-(A4) and let $\varphi$ be a lower semicontinuous and convex function from $C$ to $R$. Let $r>0$ and define a mapping $\Phi_{r}: E \rightarrow C$ as follows:

$$
\Phi_{r}(x)=\left\{z \in C: f(z, y)+\langle T z, \eta(y, z)\rangle+\varphi(y)+\frac{1}{r}\langle y-z, J(z-x)\rangle \geq \varphi(z), \forall y \in C\right\}
$$


for all $x \in E$. Assume that

(i) $\eta(x, y)+\eta(y, x)=0$, for all $x, y \in C$;

(ii) for any fixed $u, v \in C$, the mapping $x \mapsto\langle T v, \eta(x, u)\rangle$ is convex and lower semicontinuous and the mapping $x \mapsto\langle T u, \eta(v, x)\rangle$ is lower semicontinuous;

(iii) $\xi: E \rightarrow \mathcal{R}$ is weakly lower semicontinuous;

(iv) for any $x, y \in C, \xi(x-y)+\xi(y-x) \geq 0$.

Then, the following holds:

(1) $\Phi_{r}$ is single valued;

(2) $\left\langle\Phi_{r} x-\Phi_{r} y, J\left(\Phi_{r} x-x\right)\right\rangle \leq\left\langle\Phi_{r} x-\Phi_{r} y, J\left(\Phi_{r} y-y\right)\right\rangle$ for all $x, y \in E$;

(3) $F\left(\Phi_{r}\right)=\operatorname{EP}(f, T)$;

(4) $\mathrm{EP}(f, T)$ is nonempty closed and convex.

\section{Existence of Solutions for GMEP}

In this section, we prove the existence results of solutions for GMEP under the new conditions imposed on the bifunction $f$.

Theorem 3.1. Let $C$ be a nonempty, bounded, closed, and convex subset of a smooth, strictly convex, and reflexive Banach space $E$, let $T: C \rightarrow E^{*}$ be an $\eta$-hemicontinuous and relaxed $\eta-\xi$ monotone mapping. Let $f$ be a bifunction from $C \times C$ to $\mathbb{R}$ satisfying the following conditions (A1)-(A4):

(A1) $f(x, x)=0$ for all $x \in C$;

(A2) $f(x, y)+f(y, x) \leq \min \{\xi(x-y), \xi(y-x)\}$ for all $x, y \in C$;

(A3) for all $y \in C, f(\cdot, y)$ is weakly upper semicontinuous;

(A4) for all $x \in C, f(x, \cdot)$ is convex.

For any $r>0$ and $x \in E$, define a mapping $\Phi_{r}: E \rightarrow C$ as follows:

$$
\Phi_{r}(x)=\left\{z \in C: f(z, y)+\langle T z, \eta(y, z)\rangle+\varphi(y)+\frac{1}{r}\langle y-z, J(z-x)\rangle \geq \varphi(z), \forall y \in C\right\}
$$

where $\varphi$ is a lower semicontinuous and convex function from $C$ to $\mathbb{R}$. Assume that

(i) $\eta(x, y)+\eta(y, x)=0$, for all $x, y \in C$;

(ii) for any fixed $u, v \in C$, the mapping $x \mapsto\langle T v, \eta(x, u)\rangle$ is convex and lower semicontinuous and the mapping $x \mapsto\langle T u, \eta(v, x)\rangle$ is lower semicontinuous;

(iii) $\xi: E \rightarrow \mathbb{R}$ is weakly lower semicontinuous.

Then, the following holds:

(1) $\Phi_{r}$ is single valued;

(2) $\left\langle\Phi_{r} x-\Phi_{r} y, J\left(\Phi_{r} x-x\right)\right\rangle \leq\left\langle\Phi_{r} x-\Phi_{r} y, J\left(\Phi_{r} y-y\right)\right\rangle$ for all $x, y \in E$; 
(3) $F\left(\Phi_{r}\right)=\operatorname{GMEP}(f, T)$;

(4) $\operatorname{GMEP}(f, T)$ is nonempty closed and convex.

Proof. For each $x \in E$. It follows from Lemma 2.5 that $\Phi_{r}(x)$ is nonempty.

Then

(1) We prove that $\Phi_{r}$ is single valued. Indeed, for $x \in E$ and $r>0$, let $z_{1}, z_{2} \in \Phi_{r} x$.

$$
\begin{aligned}
& f\left(z_{1}, z_{2}\right)+\left\langle T z_{2}, \eta\left(z_{2}, z_{1}\right)\right\rangle+\varphi\left(z_{2}\right)+\frac{1}{r}\left\langle z_{1}-z_{2}, J\left(z_{1}-x\right)\right\rangle \geq \varphi\left(z_{1}\right) \\
& f\left(z_{2}, z_{1}\right)+\left\langle T z_{1}, \eta\left(z_{1}, z_{2}\right)\right\rangle+\varphi\left(z_{1}\right)+\frac{1}{r}\left\langle z_{2}-z_{1}, J\left(z_{2}-x\right)\right\rangle \geq \varphi\left(z_{2}\right) .
\end{aligned}
$$

Adding the two inequalities, from (i) we have

$$
f\left(z_{2}, z_{1}\right)+f\left(z_{1}, z_{2}\right)+\left\langle T z_{1}-T z_{2}, \eta\left(z_{2}, z_{1}\right)\right\rangle+\frac{1}{r}\left\langle z_{2}-z_{1}, J\left(z_{1}-x\right)-J\left(z_{2}-x\right)\right\rangle \geq 0 .
$$

Setting $\Delta:=\min \left\{\xi\left(z_{1}-z_{2}\right), \xi\left(z_{2}-z_{1}\right)\right\}$ and using (A2), we have

$$
\Delta+\left\langle T z_{1}-T z_{2}, \eta\left(z_{2}, z_{1}\right)\right\rangle+\frac{1}{r}\left\langle z_{2}-z_{1}, J\left(z_{1}-x\right)-J\left(z_{2}-x\right)\right\rangle \geq 0,
$$

that is,

$$
\frac{1}{r}\left\langle z_{2}-z_{1}, J\left(z_{1}-x\right)-J\left(z_{2}-x\right)\right\rangle \geq\left\langle T z_{2}-T z_{1}, \eta\left(z_{2}, z_{1}\right)\right\rangle-\Delta
$$

Since $T$ is relaxed $\eta-\xi$ monotone and $r>0$, one has

$$
\left\langle z_{2}-z_{1}, J\left(z_{1}-x\right)-J\left(z_{2}-x\right)\right\rangle \geq r\left(\xi\left(z_{2}-z_{1}\right)-\Delta\right) \geq 0 .
$$

In (3.5) exchanging the position of $z_{1}$ and $z_{2}$, we get

$$
\frac{1}{r}\left\langle z_{1}-z_{2}, J\left(z_{2}-x\right)-J\left(z_{1}-x\right)\right\rangle \geq\left\langle T z_{1}-T z_{2}, \eta\left(z_{1}, z_{2}\right)\right\rangle-\Delta,
$$

that is,

$$
\left\langle z_{1}-z_{2}, J\left(z_{2}-x\right)-J\left(z_{1}-x\right)\right\rangle \geq r\left(\xi\left(z_{1}-z_{2}\right)-\Delta\right) \geq 0 .
$$

Now, adding the inequalities (3.6) and (3.8), we have

$$
2\left\langle z_{2}-z_{1}, J\left(z_{1}-x\right)-J\left(z_{2}-x\right)\right\rangle \geq 0
$$


Hence,

$$
0 \leq\left\langle z_{2}-z_{1}, J\left(z_{1}-x\right)-J\left(z_{2}-x\right)\right\rangle=\left\langle\left(z_{2}-x\right)-\left(z_{1}-x\right), J\left(z_{1}-x\right)-J\left(z_{2}-x\right)\right\rangle
$$

Since $J$ is monotone and $E$ is strictly convex, we obtain that $z_{1}-x=z_{2}-x$ and hence $z_{1}=z_{2}$. Therefore $S_{r}$ is single valued.

(2) For $x, y \in C$, we have

$$
\begin{aligned}
& f\left(\Phi_{r} x, \Phi_{r} y\right)+\left\langle T \Phi_{r} x, \eta\left(\Phi_{r} y, \Phi_{r} x\right)\right\rangle+\varphi\left(\Phi_{r} y\right)-\varphi\left(\Phi_{r} x\right)+\frac{1}{r}\left\langle\Phi_{r} y-\Phi_{r} x, J\left(\Phi_{r} x-x\right)\right\rangle \geq 0, \\
& f\left(\Phi_{r} y, \Phi_{r} x\right)+\left\langle T \Phi_{r} y, \eta\left(\Phi_{r} x, \Phi_{r} y\right)\right\rangle+\varphi\left(\Phi_{r} x\right)-\varphi\left(\Phi_{r} y\right)+\frac{1}{r}\left\langle\Phi_{r} x-\Phi_{r} y, J\left(\Phi_{r} y-y\right)\right\rangle \geq 0 .
\end{aligned}
$$

Setting $\Lambda_{x, y}:=\min \left\{\xi\left(\Phi_{r} x-\Phi_{r} y\right), \xi\left(\Phi_{r} y-\Phi_{r} x\right)\right\}$ and applying (A2), we get

$$
\left\langle T \Phi_{r} x-T \Phi_{r} y, \eta\left(\Phi_{r} y, \Phi_{r} x\right)\right\rangle+\frac{1}{r}\left\langle\Phi_{r} y-\Phi_{r} x, J\left(\Phi_{r} x-x\right)-J\left(\Phi_{r} y-y\right)\right\rangle \geq-\Lambda_{x, y}
$$

that is,

$$
\begin{aligned}
\frac{1}{r}\left\langle\Phi_{r} y-\Phi_{r} x, J\left(\Phi_{r} x-x\right)-J\left(\Phi_{r} y-y\right)\right\rangle & \geq\left\langle T \Phi_{r} y-T \Phi_{r} x, \eta\left(\Phi_{r} y, \Phi_{r} x\right)\right\rangle-\Lambda_{x, y} \\
& \geq \xi\left(\Phi_{r} y-\Phi_{r} x\right)-\Lambda_{x, y} \geq 0 .
\end{aligned}
$$

In (3.13) exchanging the position of $\Phi_{r} x$ and $\Phi_{r} y$, we get

$$
\frac{1}{r}\left\langle\Phi_{r} x-\Phi_{r} y, J\left(\Phi_{r} y-y\right)-J\left(\Phi_{r} x-x\right)\right\rangle \geq 0 .
$$

Adding the inequalities (3.13) and (3.14), we have

$$
\frac{2}{r}\left\langle\Phi_{r} y-\Phi_{r} x, J\left(\Phi_{r} x-x\right)-J\left(\Phi_{r} y-y\right)\right\rangle \geq 0 .
$$

It follows that

$$
\left\langle\Phi_{r} y-\Phi_{r} x, J\left(\Phi_{r} x-x\right)-J\left(\Phi_{r} y-y\right)\right\rangle \geq 0 .
$$

Hence

$$
\left\langle\Phi_{r} x-\Phi_{r} y, J\left(\Phi_{r} x-x\right)\right\rangle \leq\left\langle\Phi_{r} x-\Phi_{r} y, J\left(\Phi_{r} y-y\right)\right\rangle .
$$

The conclusions (3), (4) follow from Lemma 2.6. 
Example 3.2. Define $\xi: \mathbb{R} \rightarrow \mathbb{R}$ and $f: \mathbb{R} \times \mathbb{R} \rightarrow \mathbb{R}$ by

$$
f(x, y)=\frac{(x-y)^{2}}{2}, \quad \xi(x)=x^{2} \quad \forall x, y \in \mathbb{R}
$$

It is easy to see that $f$ satisfies (A1), (A3), (A4), and (A2): $f(x, y)+f(y, x) \leq \min \{\xi(x-$ $y), \xi(x-y)\}$, for all $(x, y) \in \mathbb{R} \times \mathbb{R}$.

Remark 3.3. Theorem 3.1 generalizes and improves [7, Lemma 3.3] in the following manners.

(1) The condition $f(x, y)+f(y, x) \leq 0$ has been weakened by (A2) that is $f(x, y)+$ $f(y, x) \leq \min \{\xi(x-y), \xi(y-x)\}$ for all $x, y \in C$.

(2) The control condition $\xi(x-y)+\xi(y-x) \geq 0$ imposed on the mapping $\xi$ in [7, Lemma 3.3] can be removed.

If $T$ is monotone that is $T$ is relaxed $\eta-\xi$ monotone with $\eta(x, y)=x-y$ for all $x, y \in C$ and $\xi=0$, we have the following results.

Corollary 3.4. Let $C$ be a nonempty, bounded, closed, and convex subset of a smooth, strictly convex, and reflexive Banach space $E$. Let $T: C \rightarrow E^{*}$ be a monotone mapping and $f$ be a bifunction from $C \times C$ to $\mathbb{R}$ satisfying the following conditions (i)-(iv):

(i) $f(x, x)=0$ for all $x \in C$;

(ii) $f(x, y)+f(y, x) \leq 0$ for all $x, y \in C$;

(iii) for all $y \in C, f(\cdot, y)$ is weakly upper semicontinuous;

(iv) for all $x \in C, f(x, \cdot)$ is convex.

For any $r>0$ and $x \in E$, define a mapping $\Phi_{r}: E \rightarrow C$ as follows:

$$
\Phi_{r}(x)=\left\{z \in C: f(z, y)+\langle T z, y-z\rangle+\varphi(y)+\frac{1}{r}\langle y-z, J(z-x)\rangle \geq \varphi(z), \forall y \in C\right\},
$$

where $\varphi$ is a lower semicontinuous and convex function from $C$ to $\mathbb{R}$. Then, the following holds:

(1) $\Phi_{r}$ is single valued;

(2) $\left\langle\Phi_{r} x-\Phi_{r} y, J\left(\Phi_{r} x-x\right)\right\rangle \leq\left\langle\Phi_{r} x-\Phi_{r} y, J\left(\Phi_{r} y-y\right)\right\rangle$ for all $x, y \in E$;

(3) $F\left(\Phi_{r}\right)=\operatorname{GEP}(f)$;

(4) $\operatorname{GEP}(f)$ is nonempty closed and convex.

\section{Strong Convergence Theorems}

In this section, we prove the strong convergence theorem of the sequence $\left\{x_{n}\right\}$ defined by (1.20) for solving a common element in the solution set of a generalized mixed equilibrium problem and the common fixed point set of a finite family of asymptotically nonexpansive mappings. 
Theorem 4.1. Let $E$ be a uniformly convex and smooth Banach space and let $C$ be a nonempty, bounded, closed, and convex subset of $E$. Let $f$ be a bifunction from $C \times C$ to $\mathbb{R}$ satisfying (A1)(A4). Let $T: C \rightarrow E^{*}$ be an $\eta$-hemicontinuous and relaxed $\eta-\xi$ monotone mapping and $\varphi$ a lower semicontinuous and convex function from $C$ to $\mathbb{R}$. Let, for each $1 \leq i \leq N, S_{i}: C \rightarrow C$ be an asymptotically nonexpansive mapping with a sequence $\left\{k_{n, i}\right\}_{n=1}^{\infty}$, respectively, such that $k_{n, i} \rightarrow 1$ as $n \rightarrow \infty$. Assume that $\Omega:=\bigcap_{i=1}^{N} F\left(S_{i}\right) \cap \operatorname{GMEP}(f, T)$ is nonempty. Let $\left\{x_{n}\right\}$ be a sequence generated by (1.20), where $\left\{t_{n}\right\}$ and $\left\{r_{n}\right\}$ are real sequences in $(0,1)$ satisfying $\lim _{n \rightarrow \infty} t_{n}=0$ and $\liminf _{n \rightarrow \infty} r_{n}>0$. Then $\left\{x_{n}\right\}$ converges strongly, as $n \rightarrow \infty$, to $P_{\Omega} x_{0}$, where $P_{\Omega}$ is the metric projection of $E$ onto $\Omega$.

Proof. First, define the sequence $\left\{k_{n}\right\}$ by $k_{n}:=\max \left\{k_{n, i}: 1 \leq i \leq N\right\}$ and so $k_{n} \rightarrow 1$ as $n \rightarrow \infty$ and

$$
\left\|S_{i(n)}^{h(n)} x-S_{i(n)}^{h(n)} y\right\| \leq k_{n}\|x-y\| \quad \forall x, y \in C
$$

where $h(n)=j+1$ if $j N<n \leq(j+1) N, j=1,2 \ldots, N$ and $n=j N+i(n) ; i(n) \in\{1,2, \ldots, N\}$. Next, we rewrite the algorithm (1.20) as the following relation:

$$
\begin{gathered}
x_{0} \in C, \quad D_{0}=C_{0}=C, \\
C_{n}=\overline{\mathrm{co}}\left\{z \in C_{n-1}:\left\|z-S_{i(n)}^{h(n)} z\right\| \leq t_{n}\left\|x_{n}-S_{i(n)}^{h(n)} x_{n}\right\|\right\}, \quad n \geq 0, \\
D_{n}=\left\{z \in D_{n-1}:\left\langle\Phi_{r_{n}} x_{n}-z, J\left(x_{n}-\Phi_{r_{n}} x_{n}\right)\right\rangle \geq 0\right\}, \quad n \geq 1, \\
x_{n+1}=P_{C_{n} \cap D_{n}} x_{0}, \quad n \geq 0,
\end{gathered}
$$

where $\Phi_{r}$ is the mapping defined by (3.19). We show that the sequence $\left\{x_{n}\right\}$ is well defined. It is easy to verify that $C_{n} \cap D_{n}$ is closed and convex and $\Omega \subset C_{n}$ for all $n \geq 0$. Next, we prove that $\Omega \subset C_{n} \cap D_{n}$. Indeed, since $D_{0}=C$, we also have $\Omega \subset C_{0} \cap D_{0}$. Assume that $\Omega \subset C_{k-1} \cap D_{k-1}$ for $k \geq 2$. Utilizing Theorem 3.1 (2), we obtain

$$
\left\langle\Phi_{r_{k}} x_{k}-\Phi_{r_{k}} u, J\left(\Phi_{r_{k}} u-u\right)-J\left(\Phi_{r_{k}} x_{k}-x_{k}\right)\right\rangle \geq 0, \quad \forall u \in \Omega,
$$

which gives that

$$
\left\langle\Phi_{r_{k}} x_{k}-u, J\left(x_{k}-\Phi_{r_{k}} x_{k}\right)\right\rangle \geq 0, \quad \forall u \in \Omega,
$$

hence $\Omega \subset D_{k}$. By the mathematical induction, we get that $\Omega \subset C_{n} \cap D_{n}$ for each $n \geq 0$ and hence $\left\{x_{n}\right\}$ is well defined. Now, we show that

$$
\lim _{n \rightarrow \infty}\left\|x_{n}-x_{n+j}\right\|=0, \quad \forall j=1,2, \ldots, N
$$

Put $w=P_{\Omega} x_{0}$, since $\Omega \subset C_{n} \cap D_{n}$ and $x_{n+1}=P_{C_{n} \cap D_{n}}$, we have

$$
\left\|x_{n+1}-x_{0}\right\| \leq\left\|w-x_{0}\right\|, \quad \forall n \geq 0 .
$$


Since $x_{n+2} \in D_{n+1} \subset D_{n}$ and $x_{n+1}=P_{C_{n} \cap D_{n}} x_{0}$, we have

$$
\left\|x_{n+1}-x_{0}\right\| \leq\left\|x_{n+2}-x_{0}\right\|
$$

Hence the sequence $\left\{\left\|x_{n}-x_{0}\right\|\right\}$ is bounded and monotone increasing and hence there exists a constant $d$ such that

$$
\lim _{n \rightarrow \infty}\left\|x_{n}-x_{0}\right\|=d
$$

Moreover, by the convexity of $D_{n}$, we also have $1 / 2\left(x_{n+1}+x_{n+2}\right) \in D_{n}$ and hence

$$
\left\|x_{0}-x_{n+1}\right\| \leq\left\|x_{0}-\frac{x_{n+1}+x_{n+2}}{2}\right\| \leq \frac{1}{2}\left(\left\|x_{0}-x_{n+1}\right\|+\left\|x_{0}-x_{n+2}\right\|\right) .
$$

This implies that

$$
\lim _{n \rightarrow \infty}\left\|\frac{1}{2}\left(x_{0}-x_{n+1}\right)+\frac{1}{2}\left(x_{0}-x_{n+2}\right)\right\|=\lim _{n \rightarrow \infty}\left\|x_{0}-\frac{x_{n+1}+x_{n+2}}{2}\right\|=d
$$

By Lemma 2.2, we have

$$
\lim _{n \rightarrow \infty}\left\|x_{n}-x_{n+1}\right\|=0
$$

Furthermore, we can easily see that

$$
\lim _{n \rightarrow \infty}\left\|x_{n}-x_{n+j}\right\|=0, \quad \forall j=1,2, \ldots, N .
$$

Next, we show that

$$
\lim _{n \rightarrow \infty}\left\|x_{n}-S_{i(n-\kappa)}^{h(n-\kappa)} x_{n}\right\|=0, \quad \text { for any } \kappa \in\{1,2, \ldots, N\}
$$

Fix $\kappa \in\{1,2, \ldots, N\}$ and put $m=n-\kappa$. Since $x_{n}=P_{C_{n-1} \cap D_{n-1}} x$, we have $x_{n} \in C_{n-1} \subseteq \cdots \subseteq C_{m}$. Since $t_{m}>0$, there exists $y_{1}, \ldots, y_{P} \in C$ and a nonnegative number $\lambda_{1}, \ldots, \lambda_{P}$ with $\lambda_{1}+\cdots+\lambda_{P}=$ 1 such that

$$
\begin{gathered}
\left\|x_{n}-\sum_{i=1}^{P} \lambda_{i} y_{i}\right\|<t_{m}, \\
\left\|y_{i}-S_{i(m)}^{h(m)} y_{i}\right\| \leq t_{m}\left\|x_{m}-S_{i(m)}^{h(m)} x_{m}\right\|, \quad \forall i \in\{1, \ldots, P\} .
\end{gathered}
$$

By the boundedness of $C$ and $\left\{k_{n}\right\}$, we can put the following:

$$
M=\sup _{x \in C}\|x\|, \quad u=P_{\bigcap_{i=1}^{N} F\left(S_{i}\right)} x_{0}, \quad r_{0}=\sup _{n \geq 1}\left(1+k_{n}\right)\left\|x_{n}-u\right\| .
$$


Journal of Applied Mathematics

This together with (4.14) implies that

$$
\begin{aligned}
\left\|x_{n}-\frac{1}{k_{m}} \sum_{i=1}^{P} \lambda_{i} y_{i}\right\| \leq(1 & \left.-\frac{1}{k_{m}}\right)\|x\|+\frac{1}{k_{m}}\left\|x_{n}-\sum_{i=1}^{P} \lambda_{i} y_{i}\right\| \leq\left(1-\frac{1}{k_{m}}\right) M+t_{m}, \\
\left\|y_{i}-S_{i(m)}^{h(m)} y_{i}\right\| & \leq t_{m}\left\|x_{m}-S_{i(m)}^{h(m)} x_{m}\right\| \\
& \leq t_{m}\left\|x_{m}-S_{i(m)}^{h(m)} u\right\|+t_{m}\left\|S_{i(m)}^{h(m)} u-S_{i(m)}^{h(m)} x_{m}\right\| \\
& \leq t_{m}\left\|x_{m}-u\right\|+t_{m} k_{m}\left\|u-x_{m}\right\| \\
& \leq t_{m}\left(1+k_{m}\right)\left\|x_{m}-u\right\| \\
& \leq t_{m} r_{0},
\end{aligned}
$$

for all $i \in\{1, \ldots, N\}$. Therefore, for each $i \in\{1, \ldots, P\}$, we get

$$
\begin{aligned}
\left\|y_{i}-\frac{1}{k_{m}} S_{i(m)}^{h(m)} y_{i}\right\| & \leq\left\|y_{i}-S_{i(m)}^{h(m)} y_{i}\right\|+\left\|S_{i(m)}^{h(m)} y_{i}-\frac{1}{k_{m}} S_{i(m)}^{h(m)} y_{i}\right\| \\
& \leq r_{0} t_{m}+\left(1-\frac{1}{k_{m}}\right) M .
\end{aligned}
$$

Moreover, since each $S_{i}, i \in\{1,2, \ldots, N\}$, is asymptotically nonexpansive, we can obtain that

$$
\begin{aligned}
\left\|\frac{1}{k_{m}} S_{i(m)}^{h(m)}\left(\sum_{i=1}^{P} \lambda_{i} y_{i}\right)-S_{i(m)}^{h(m)} x_{n}\right\| \leq & \left\|\frac{1}{k_{m}} S_{i(m)}^{h(m)}\left(\sum_{i=1}^{P} \lambda_{i} y_{i}\right)-\frac{1}{k_{m}} S_{i(m)}^{h(m)} x_{n}\right\| \\
& +\left\|\frac{1}{k_{m}} S_{i(m)}^{h(m)} x_{n}-S_{i(m)}^{h(m)} x_{n}\right\| \\
\leq & \left\|\sum_{i=1}^{P} \lambda_{i} y_{i}-x_{n}\right\|+\left(1-\frac{1}{k_{m}}\right) M \\
& =t_{m}+\left(1-\frac{1}{k_{m}}\right) M .
\end{aligned}
$$

It follows from Theorem 2.3 and the inequalities (4.17)-(4.19) that

$$
\begin{aligned}
\left\|x_{n}-S_{i(m)}^{h(m)} x_{n}\right\| \leq & \left\|x_{n}-\frac{1}{k_{m}} \sum_{i=1}^{P} \lambda_{i} y_{i}\right\|+\frac{1}{k_{m}}\left\|\sum_{i=1}^{P} \lambda_{i}\left(y_{i}-S_{i(m)}^{h(m)} y_{i}\right)\right\| \\
& +\frac{1}{k_{m}}\left\|\sum_{i=1}^{P} \lambda_{i} S_{i(m)}^{h(m)} y_{i}-S_{i(m)}^{h(m)}\left(\sum_{i=1}^{P} \lambda_{i} y_{i}\right)\right\|+\left\|\frac{1}{k_{m}} S_{i(m)}^{h(m)}\left(\sum_{i=1}^{P} \lambda_{i} y_{i}\right)-S_{i(m)}^{h(m)} x_{n}\right\|
\end{aligned}
$$




$$
\begin{aligned}
\leq & 2\left[\left(1-\frac{1}{k_{m}}\right) M+t_{m}\right]+\frac{r_{0} t_{m}}{k_{m}} \\
& +r^{-1}\left(\max _{1 \leq i \leq j \leq N}\left(\left\|y_{i}-y_{j}\right\|-\frac{1}{k_{m}}\left\|S_{i(m)}^{h(m)} y_{i}-S_{i(m)}^{h(m)} y_{j}\right\|\right)\right) \\
= & 2\left(1-\frac{1}{k_{m}}\right) M+2 t_{m}+\frac{r_{0} t_{m}}{k_{m}} \\
& +r^{-1}\left(\max _{1 \leq i \leq j \leq N}\left(\left\|y_{i}-y_{j}\right\|-\frac{1}{k_{m}}\left\|S_{i(m)}^{h(m)} y_{i}-S_{i(m)}^{h(m)} y_{j}\right\|\right)\right) \\
\leq & 2\left(1-\frac{1}{k_{m}}\right) M+2 t_{m}+\frac{r_{0} t_{m}}{k_{m}} \\
& +r^{-1}\left(\max _{1 \leq i \leq j \leq N}\left(\left\|y_{i}-\frac{1}{k_{m}} S_{i(m)}^{h(m)} y_{i}\right\|+\left\|y_{j}-\frac{1}{k_{m}} S_{i(m)}^{h(m)} y_{j}\right\|\right)\right) \\
\leq & 2\left(1-\frac{1}{k_{m}}\right) M+2 t_{m}+\frac{r_{0} t_{m}}{k_{m}}+r^{-1}\left(2\left(1-\frac{1}{k_{m}}\right) M+2 r_{0} t_{m}\right) .
\end{aligned}
$$

Since $\lim _{n \rightarrow \infty} k_{n}=1$ and $\lim _{n \rightarrow \infty} t_{n}=0$, it follows from the above inequality that

$$
\lim _{n \rightarrow \infty}\left\|x_{n}-S_{i(m)}^{h(m)} x_{n}\right\|=0
$$

Hence (4.13) is proved. Next, we show that

$$
\lim _{n \rightarrow \infty}\left\|x_{n}-S_{l} x_{n}\right\|=0 ; \quad \forall l=1,2, \ldots, N
$$

From the construction of $C_{n}$, one can easily see that

$$
\left\|x_{n+1}-S_{i(n)}^{h(n)} x_{n+1}\right\| \leq t_{n}\left\|x_{n}-S_{i(n)}^{h(n)} x_{n}\right\| .
$$

The boundedness of $C$ and $\lim _{n \rightarrow \infty} t_{n}=0$ implies that

$$
\lim _{n \rightarrow \infty}\left\|x_{n+1}-S_{i(n)}^{h(n)} x_{n+1}\right\|=0 .
$$

On the other hand, since for any positive integer $n>N, n=(n-N)(\bmod N)$ and $n=(h(n)-$ 1) $N+i(n)$, we have

$$
n-N=(h(n)-1) N+i(n)=(h(n-N)-1) N+i(n-N)
$$

that is

$$
h(n-N)=h(n)-1, \quad i(n-N)=i(n) .
$$


Thus,

$$
\begin{aligned}
\left\|x_{n}-S_{n} x_{n}\right\| \leq & \left\|x_{n}-x_{n+1}\right\|+\left\|x_{n+1}-S_{i(n)}^{h(n)} x_{n+1}\right\|+\left\|S_{i(n)}^{h(n)} x_{n+1}-S_{n} x_{n}\right\| \\
\leq & \left\|x_{n}-x_{n+1}\right\|+\left\|x_{n+1}-S_{i(n)}^{h(n)} x_{n+1}\right\|+\left\|S_{i(n)}^{h(n)} x_{n+1}-S_{n} x_{n+1}\right\|+\left\|S_{n} x_{n+1}-S_{n} x_{n}\right\| \\
\leq & \left(1+k_{1}\right)\left\|x_{n}-x_{n+1}\right\|+\left\|x_{n+1}-S_{i(n)}^{h(n)} x_{n+1}\right\|+k_{1}\left\|S_{i(n)}^{h(n)-1} x_{n+1}-x_{n+1}\right\| \\
\leq & \left(1+k_{1}\right)\left\|x_{n}-x_{n+1}\right\|+\left\|x_{n+1}-S_{i(n)}^{h(n)} x_{n+1}\right\| \\
& +k_{1}\left[\left\|S_{i(n)}^{h(n)-1} x_{n+1}-S_{i(n)}^{h(n)-1} x_{n}\right\|+\left\|S_{i(n)}^{h(n)-1} x_{n}-x_{n}\right\|+\left\|x_{n}-x_{n+1}\right\|\right] \\
\leq & \left(1+2 k_{1}\right)\left\|x_{n}-x_{n+1}\right\|+\left\|x_{n+1}-S_{i(n)}^{h(n)} x_{n+1}\right\| \\
& +k_{1}\left\|S_{i(n-N)}^{h(n-N)} x_{n+1}-S_{i(n-N)}^{h(n-N)} x_{n}\right\|+k_{1}\left\|S_{i(n-N)}^{h(n-N)} x_{n}-x_{n}\right\| \\
\leq & \left(1+2 k_{1}\right)\left\|x_{n}-x_{n+1}\right\|+\left\|x_{n+1}-S_{i(n)}^{h(n)} x_{n+1}\right\| \\
& +k_{1} k_{n-N}\left\|x_{n+1}-x_{n}\right\|+k_{1}\left\|S_{i(n-N)}^{h(n-N)} x_{n}-x_{n}\right\| \\
\leq & \left(1+2 k_{1}+k_{1} k_{n-N}\right)\left\|x_{n}-x_{n+1}\right\|+\left\|x_{n+1}-S_{i(n)}^{h(n)} x_{n+1}\right\|+k_{1}\left\|S_{i(n-N)}^{h(n-N)} x_{n}-x_{n}\right\| .
\end{aligned}
$$

Applying the facts (4.11), (4.13), and (4.24) to the above inequality, we obtain

$$
\lim _{n \rightarrow \infty}\left\|x_{n}-S_{n} x_{n}\right\|=0
$$

Therefore, for any $j=1,2, \ldots, N$, we have

$$
\begin{aligned}
\left\|x_{n}-S_{n+j} x_{n}\right\| & \leq\left\|x_{n}-x_{n+j}\right\|+\left\|x_{n+j}-S_{n+j} x_{n+j}\right\|+\left\|S_{n+j} x_{n+j}-S_{n+j} x_{n}\right\| \\
& \leq\left\|x_{n}-x_{n+j}\right\|+\left\|x_{n+j}-S_{n+j} x_{n+j}\right\|+k_{1}\left\|x_{n+j}-x_{n}\right\| \\
& =\left(1+k_{1}\right)\left\|x_{n}-x_{n+j}\right\|+\left\|x_{n+j}-S_{n+j} x_{n+j}\right\| \longrightarrow 0 \text { as } n \longrightarrow \infty,
\end{aligned}
$$

which gives that

$$
\lim _{n \rightarrow \infty}\left\|x_{n}-S_{l} x_{n}\right\|=0 ; \quad \forall l=1,2, \ldots, N,
$$

as required. Since $\left\{x_{n}\right\}$ is bounded, there exists a subsequence $\left\{x_{n_{i}}\right\}$ of $\left\{x_{n}\right\}$ such that $x_{n_{i}} \rightarrow$ $\tilde{x} \in C$. It follows from Lemma 2.4 that $\tilde{x} \in F\left(S_{l}\right)$ for all $l=1,2, \ldots, N$. That is $x \in \bigcap_{i=1}^{N} F\left(S_{i}\right)$.

Next, we show that $\tilde{x} \in \operatorname{GMEP}(f, T)$. By the construction of $D_{n}$, we see from Theorem 2.1 that $\Phi_{r_{n}} x_{n}=P_{D_{n}} x_{n}$. Since $x_{n+1} \in D_{n}$, we get

$$
\left\|x_{n}-\Phi_{r_{n}} x_{n}\right\| \leq\left\|x_{n}-x_{n+1}\right\| \longrightarrow 0 .
$$


Furthermore, since $\liminf _{n \rightarrow \infty} r_{n}>0$, we have

$$
\frac{1}{r_{n}}\left\|J\left(x_{n}-\Phi_{r_{n}} x_{n}\right)\right\|=\frac{1}{r_{n}}\left\|x_{n}-\Phi_{r_{n}} x_{n}\right\| \longrightarrow 0
$$

as $n \rightarrow \infty$. By (4.32), we also have $\Phi_{r_{n_{i}}} x_{n_{i}} \rightarrow \tilde{x}$. By the definition of $\Phi_{r_{n_{i}}}$, for each $y \in C$, we obtain

$$
\begin{aligned}
& f\left(\Phi_{r_{n_{i}}} x_{n_{i}}, y\right)+\left\langle T \Phi_{r_{n_{i}}} x_{n_{i}}, \eta\left(y, \Phi_{r_{n_{i}}} x_{n_{i}}\right)\right\rangle+\varphi(y)+\frac{1}{r_{n_{i}}}\left\langle y-\Phi_{r_{n_{i}}} x_{n_{i}}, J\left(\Phi_{r_{n_{i}}} x_{n_{i}}-x_{n_{i}}\right)\right\rangle \\
& \quad \geq \varphi\left(\Phi_{r_{n_{i}}} x_{n_{i}}\right) .
\end{aligned}
$$

By (A3), (4.32), (ii), the weakly lower semicontinuity of $\varphi$ and $\eta$-hemicontinuity of $T$, we have

$$
\begin{aligned}
\varphi(\tilde{x}) \leq & \liminf _{i \rightarrow \infty} \varphi\left(\Phi_{r_{n_{i}}} x_{n_{i}}\right) \\
\leq & \liminf _{i \rightarrow \infty} f\left(\Phi_{r_{n_{i}}} x_{n_{i}}, y\right)+\liminf _{i \rightarrow \infty}\left\langle T \Phi_{r_{n_{i}}} x_{n_{i}}, \eta\left(y, \Phi_{r_{n_{i}}} x_{n_{i}}\right)\right\rangle \\
& +\varphi(y)+\liminf _{i \rightarrow \infty} \frac{1}{r_{n_{i}}}\left\langle y-\Phi_{r_{n_{i}}} x_{n_{i}} J\left(\Phi_{r_{n_{i}}} x_{n_{i}}-x_{n_{i}}\right)\right\rangle \\
\leq & f(\tilde{x}, y)+\varphi(y)+\langle T \tilde{x}, \eta(y, \tilde{x})\rangle .
\end{aligned}
$$

Hence,

$$
f(\tilde{x}, y)+\varphi(y)+\langle T \tilde{x}, \eta(y, \tilde{x})\rangle \geq \varphi(\tilde{x}) .
$$

This shows that $\tilde{x} \in \operatorname{EP}(f, T)$ and hence $\tilde{x} \in \Omega:=\bigcap_{i=1}^{N} F\left(S_{i}\right) \cap \operatorname{GMEP}(f, T)$.

Finally, we show that $x_{n} \rightarrow w$ as $n \rightarrow \infty$, where $w:=P_{\Omega} x_{0}$. By the weakly lower semicontinuity of the norm, it follows from (4.6) that

$$
\left\|x_{0}-w\right\| \leq\left\|x_{0}-\tilde{x}\right\| \leq \liminf _{i \rightarrow \infty}\left\|x_{0}-x_{n_{i}}\right\| \leq \limsup _{i \rightarrow \infty}\left\|x_{0}-x_{n_{i}}\right\| \leq\left\|x_{0}-w\right\|
$$

This shows that

$$
\lim _{i \rightarrow \infty}\left\|x_{0}-x_{n_{i}}\right\|=\left\|x_{0}-w\right\|=\left\|x_{0}-\tilde{x}\right\|
$$

and $\tilde{x}=w$. Since $E$ is uniformly convex, we obtain that $x_{0}-x_{n_{i}} \rightarrow x_{0}-w$. It follows that $x_{n_{i}} \rightarrow w$. So we have $x_{n} \rightarrow w$ as $n \rightarrow \infty$. This completes the proof. 


\section{Corollaries}

Setting $S_{i} \equiv S$, an asymptotically nonexpansive mapping, in Theorem 4.1 then we have the following result.

Theorem 5.1. Let $E$ be a uniformly convex and smooth Banach space and let $C$ be a nonempty, bounded, closed, and convex subset of $E$. Let $f$ be a bifunction from $C \times C$ to $\mathbb{R}$ satisfying (A1)(A4). Let $T: C \rightarrow E^{*}$ be an $\eta$-hemicontinuous and relaxed $\eta-\xi$ monotone mapping and $\varphi$ a lower semicontinuous and convex function from $C$ to $\mathbb{R}$. Let $S$ be an asymptotically nonexpansive mapping with a sequence $\left\{k_{n}\right\}$, such that $k_{n} \rightarrow 1$ as $n \rightarrow \infty$. Assume that $\Omega:=F(S) \cap \operatorname{GMEP}(f, T)$ is nonempty. Let $\left\{x_{n}\right\}$ be a sequence generated by

$$
\begin{gathered}
x_{0} \in C, \quad D_{0}=C_{0}=C, \\
C_{n}=\overline{\mathrm{co}}\left\{z \in C_{n-1}:\left\|z-S^{n} z\right\| \leq t_{n}\left\|x_{n}-S^{n} x_{n}\right\|\right\}, \quad n \geq 1, \\
u_{n} \in C \text { such that } f\left(u_{n}, y\right)+\varphi(y)+\left\langle T u_{n}, \eta\left(y, u_{n}\right)\right\rangle+\frac{1}{r_{n}}\left\langle y-u_{n}, J\left(u_{n}-x_{n}\right)\right\rangle, \quad \forall y \in C, n \geq 1, \\
D_{n}=\left\{z \in D_{n-1}:\left\langle u_{n}-z, J\left(x_{n}-u_{n}\right)\right\rangle \geq 0\right\}, \quad n \geq 1, \\
x_{n+1}=P_{C_{n} \cap D_{n}} x_{0}, \quad n \geq 0,
\end{gathered}
$$

where $\left\{t_{n}\right\}$ and $\left\{r_{n}\right\}$ are real sequences in $(0,1)$ satisfying $\lim _{n \rightarrow \infty} t_{n}=0$ and $\liminf _{n \rightarrow \infty} r_{n}>0$. Then $\left\{x_{n}\right\}$ converges strongly, as $n \rightarrow \infty$, to $P_{\Omega} x_{0}$, where $P_{\Omega}$ is the metric projection of $E$ onto $\Omega$.

It's well known that each nonexpansive mapping is an asymptotically nonexpansive mapping, then Theorem 4.1 works for nonexpansive mapping.

Theorem 5.2. Let $E$ be a uniformly convex and smooth Banach space and let $C$ be a nonempty, bounded, closed, and convex subset of $E$. Let $f$ be a bifunction from $C \times C$ to $\mathbb{R}$ satisfying (A1)(A4). Let $T: C \rightarrow E^{*}$ be an $\eta$-hemicontinuous and relaxed $\eta-\xi$ monotone mapping and $\varphi$ a lower semicontinuous and convex function from $C$ to $\mathbb{R}$. Let $S$ be a nonexpansive mapping of $C$ into itself such that $\Omega:=F(S) \cap \operatorname{GMEP}(f, T) \neq \emptyset$. Let $\left\{x_{n}\right\}$ be the sequence in $C$ generated by

$$
\begin{gathered}
x_{0} \in C, \quad D_{0}=C_{0}=C, \\
C_{n}=\overline{\mathrm{co}}\left\{z \in C_{n-1}:\|z-S z\| \leq t_{n}\left\|x_{n}-S x_{n}\right\|\right\}, \quad n \geq 1, \\
u_{n} \in C \text { such that } f\left(u_{n}, y\right)+\varphi(y)+\left\langle T u_{n}, \eta\left(y, u_{n}\right)\right\rangle+\frac{1}{r}\left\langle y-u_{n}, J\left(u_{n}-x_{n}\right)\right\rangle \geq \varphi\left(u_{n}\right), \\
\quad \forall y \in C, n \geq 0, \\
D_{n}=\left\{z \in D_{n-1}:\left\langle u_{n}-z, J\left(x_{n}-u_{n}\right)\right\rangle \geq 0\right\}, \quad n \geq 1, \\
x_{n+1}=P_{C_{n} \cap D_{n}} x_{0}, \quad n \geq 0,
\end{gathered}
$$

where $\left\{t_{n}\right\}$ and $\left\{r_{n}\right\}$ are real sequences in $(0,1)$ satisfying $\lim _{n \rightarrow \infty} t_{n}=0$ and $\liminf _{n \rightarrow \infty} r_{n}>0$. Then, the sequence $\left\{x_{n}\right\}$ converges strongly to $P_{\Omega} x_{0}$. 
If one takes $T \equiv 0$ and $\varphi \equiv 0$ in Theorem 4.1, then one obtains the following result concerning an equilibrium problem in a Banach space setting.

Theorem 5.3. Let $E$ be a uniformly convex and smooth Banach space and let $C$ be a nonempty, bounded, closed, and convex subset of $E$. Let $f$ be a bifunction from $C \times C$ to $\mathbb{R}$ satisfying (A1)-(A4) and let $S$ be an asymptotically nonexpansive mapping of $C$ into itself such that $\Omega:=\bigcap_{n=0}^{\infty} F\left(S_{n}\right) \cap$ $\mathrm{EP}(f) \neq \emptyset$. Let $\left\{x_{n}\right\}$ be the sequence in $C$ generated by

$$
\begin{gathered}
x_{0} \in C, \quad D_{0}=C_{0}=C, \\
C_{n}=\overline{\mathrm{co}}\left\{z \in C_{n-1}:\left\|z-S^{n} z\right\| \leq t_{n}\left\|x_{n}-S^{n} x_{n}\right\|\right\}, \quad n \geq 1, \\
u_{n} \in C \text { such that } f\left(u_{n}, y\right)+\frac{1}{r_{n}}\left\langle y-u_{n}, J\left(u_{n}-x_{n}\right)\right\rangle \geq 0, \quad \forall y \in C, n \geq 0, \\
D_{n}=\left\{z \in D_{n-1}:\left\langle u_{n}-z, J\left(x_{n}-u_{n}\right)\right\rangle \geq 0\right\}, \quad n \geq 1, \\
x_{n+1}=P_{C_{n} \cap D_{n}} x_{0}, \quad n \geq 0,
\end{gathered}
$$

where $\left\{t_{n}\right\}$ and $\left\{r_{n}\right\}$ are real sequences in $(0,1)$ satisfying $\lim _{n \rightarrow \infty} t_{n}=0$ and $\liminf _{n \rightarrow \infty} r_{n}>0$. Then the sequence $\left\{x_{n}\right\}$ converges strongly to $P_{\Omega} x_{0}$. result.

If one takes $f \equiv 0$ and $T \equiv 0$ and $\varphi \equiv 0$ in Theorem 4.1, then one obtains the following

Theorem 5.4. Let E be a uniformly convex and smooth Banach space, $C$ a nonempty, bounded, closed, and convex subset of $E$ and $S$ an asymptotically nonexpansive mapping of $C$ into itself such that $\Omega:=\bigcap_{n=0}^{\infty} F\left(S_{n}\right) \neq \emptyset$. Let $\left\{x_{n}\right\}$ be the sequence in $C$ generated by

$$
\begin{gathered}
x_{0} \in C, \quad C_{0}=C, \\
C_{n}=\overline{\operatorname{co}}\left\{z \in C_{n-1}:\left\|z-S^{n} z\right\| \leq t_{n}\left\|x_{n}-S^{n} x_{n}\right\|\right\}, \quad n \geq 1, \\
x_{n+1}=P_{C_{n}} x_{0}, \quad n \geq 0 .
\end{gathered}
$$

If $\left\{t_{n}\right\} \subset(0,1)$ and $\lim _{n \rightarrow \infty} t_{n}=0$, then $\left\{x_{n}\right\}$ converges strongly to $P_{\Omega} x_{0}$.

\section{Acknowledgments}

The first author is supported by the "Centre of Excellence in Mathematics" under the Commission on Higher Education, Ministry of Education, Thailand, and the second author is supported by grant under the program Strategic Scholarships for Frontier Research Network for the Ph.D. Program Thai Doctoral degree from the Office of the Higher Education Commission, Thailand. Finally, The authors would like to thank the referees for reading this paper carefully, providing valuable suggestions and comments, and pointing out a major error in the original version of this paper.

\section{References}

[1] K. Goebel and W. A. Kirk, "A fixed point theorem for asymptotically nonexpansive mappings," Proceedings of the American Mathematical Society, vol. 35, pp. 171-174, 1972. 
[2] R. P. Agarwal, D. O'Regan, and D. R. Sahu, Fixed Point Theory for Lipschitzian-Type Mappings with Applications, Springer, Dordrecht, The Netherlands, 2000.

[3] Y. P. Fang and N. J. Huang, "Variational-like inequalities with generalized monotone mappings in Banach spaces," Journal of Optimization Theory and Applications, vol. 118, no. 2, pp. 327-338, 2003.

[4] D. Goeleven and D. Motreanu, "Eigenvalue and dynamic problems for variational and hemivariational inequalities," Communications on Applied Nonlinear Analysis, vol. 3, no. 4, pp. 1-21, 1996.

[5] A. H. Siddiqi, Q. H. Ansari, and K. R. Kazmi, "On nonlinear variational inequalities," Indian Journal of Pure and Applied Mathematics, vol. 25, no. 9, pp. 969-973, 1994.

[6] R. U. Verma, "Nonlinear variational inequalities on convex subsets of Banach spaces," Applied Mathematics Letters, vol. 10, no. 4, pp. 25-27, 1997.

[7] U. Kamraksa and R. Wangkeeree, "Existence theorems and iterative approximation methods for generalized mixed equilibrium problems for a countable family of nonexpansivemappings," Journal of Global Optimization. In press.

[8] B. Kanster, C. Kuratowski, and S. Mazurkiewicz, "Ein Beweis des Fixpunktsatzes fur n-dimensionale Simplexe," Fundamenta Mathematicae, vol. 14, pp. 132-137, 1929.

[9] E. Blum and W. Oettli, "From optimization and variational inequalities to equilibrium problems," The Mathematics Student, vol. 63, no. 1-4, pp. 123-145, 1994.

[10] P. L. Combettes and S. A. Hirstoaga, "Equilibrium programming in Hilbert spaces," Journal of Nonlinear and Convex Analysis, vol. 6, no. 1, pp. 117-136, 2005.

[11] A. Moudafi, "Second-order differential proximal methods for equilibrium problems," Journal of Inequalities in Pure and Applied Mathematics, vol. 4, no. 1, article 18, pp. 1-7, 2003.

[12] W. R. Mann, "Mean value methods in iteration," Proceedings of the American Mathematical Society, vol. 4, pp. 506-510, 1953.

[13] A. Tada and W. Takahashi, "Strong convergence theorem for an equilibrium problem and a nonexpansive mapping," in Nonlinear Analysis and Convex Analysis, W. Takahashi and T. Tanaka, Eds., pp. 609-617, Yokohama Publishers, Yokohama, Japan, 2007.

[14] S. Y. Matsushita and W. Takahashi, "Approximating fixed points of nonexpansive mappings in a Banach space by metric projections," Applied Mathematics and Computation, vol. 196, no. 1, pp. 422$425,2008$.

[15] W. Takahashi, Y. Takeuchi, and R. Kubota, "Strong convergence theorems by hybrid methods for families of nonexpansive mappings in Hilbert spaces," Journal of Mathematical Analysis and Applications, vol. 341, no. 1, pp. 276-286, 2008.

[16] A. Tada and W. Takahashi, "Weak and strong convergence theorems for a nonexpansive mapping and an equilibrium problem," Journal of Optimization Theory and Applications, vol. 133, no. 3, pp. 359-370, 2007.

[17] S. Takahashi and W. Takahashi, "Strong convergence theorem for a generalized equilibrium problem and a nonexpansive mapping in a Hilbert space," Nonlinear Analysis, vol. 69, no. 3, pp. 1025-1033, 2008.

[18] K. Nakajo and W. Takahashi, "Strong convergence theorems for nonexpansive mappings and nonexpansive semigroups," Journal of Mathematical Analysis and Applications, vol. 279, no. 2, pp. 372-379, 2003.

[19] H. H. Bauschke, E. Matoušková, and S. Reich, "Projection and proximal point methods: convergence results and counterexamples," Nonlinear Analysis, vol. 56, no. 5, pp. 715-738, 2004.

[20] A. Genel and J. Lindenstrauss, "An example concerning fixed points," Israel Journal of Mathematics, vol. 22, no. 1, pp. 81-86, 1975.

[21] S. Reich, "Weak convergence theorems for nonexpansive mappings in Banach spaces," Journal of Mathematical Analysis and Applications, vol. 67, no. 2, pp. 274-276, 1979.

[22] H. K. Xu, "Strong convergence of approximating fixed point sequences for nonexpansive mappings," Bulletin of the Australian Mathematical Society, vol. 74, no. 1, pp. 143-151, 2006.

[23] H. Dehghan, "Approximating fixed points of asymptotically nonexpansive mappings in Banach spaces by metric projections," Applied Mathematics Letters, vol. 24, no. 9, pp. 1584-1587, 2011.

[24] Y. Kimura and K. Nakajo, "Some characterizations for a family of nonexpansive mappings and convergence of a generated sequence to their common fixed point," Fixed Point Theory and Applications, vol. 2010, Article ID 732872, 16 pages, 2010.

[25] E. Zeidler, Nonlinear Functional Analysis and Its Applications-Vol I: Fixed-Point Theorems, Springer, New York, NY, USA, 1986.

[26] Y. J. Cho, H. Zhou, and G. Guo, "Weak and strong convergence theorems for three-step iterations with errors for asymptotically nonexpansive mappings," Computers E Mathematics with Applications, vol. 47, no. 4-5, pp. 707-717, 2004. 


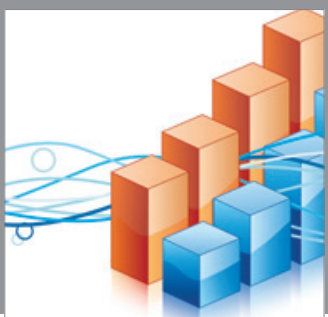

Advances in

Operations Research

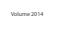

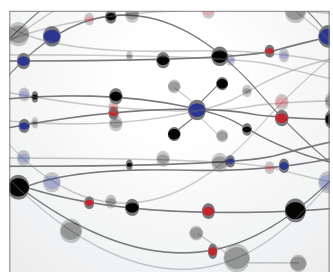

\section{The Scientific} World Journal
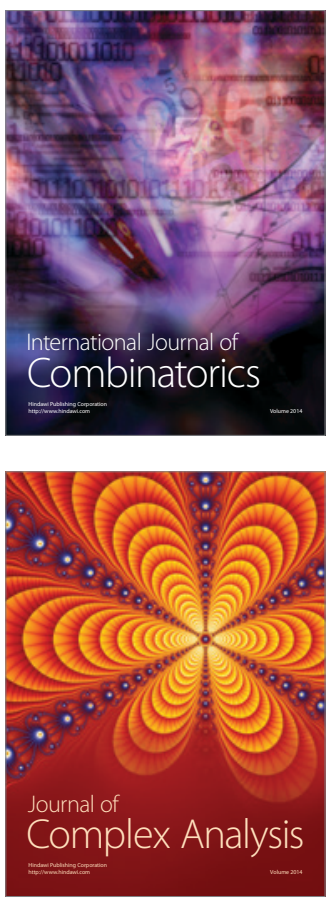

International Journal of

Mathematics and

Mathematical

Sciences
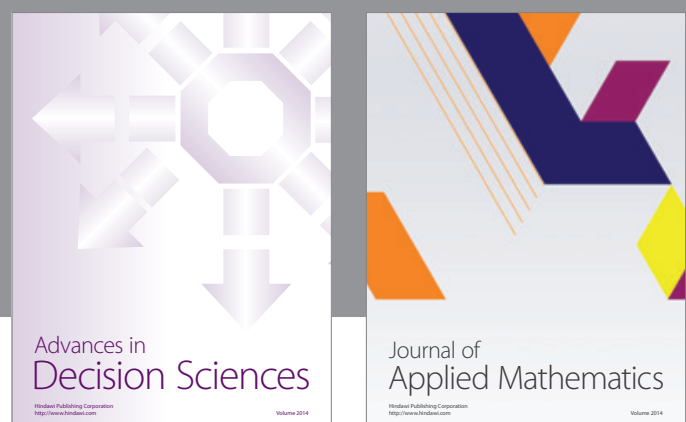

Journal of

Applied Mathematics
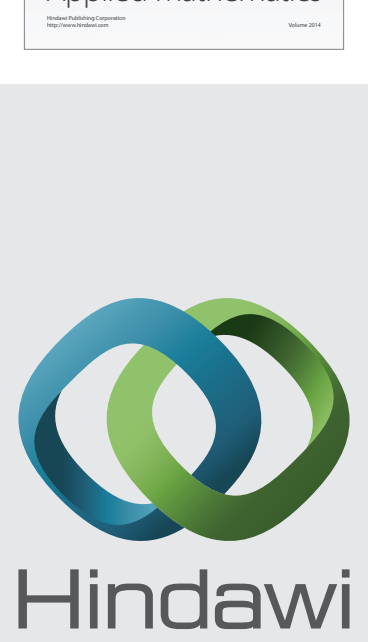

Submit your manuscripts at http://www.hindawi.com
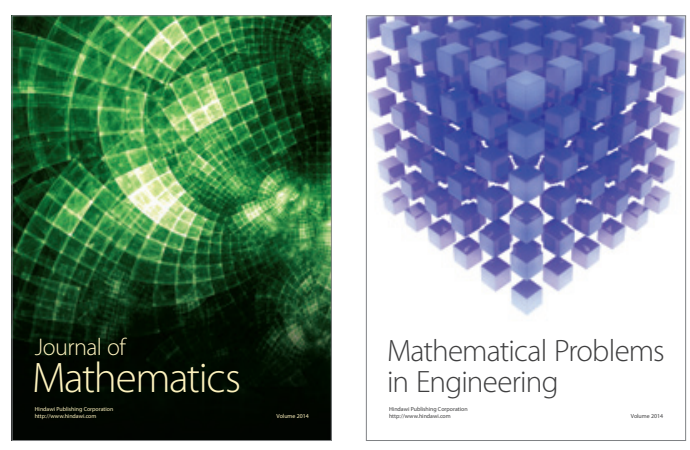

Mathematical Problems in Engineering
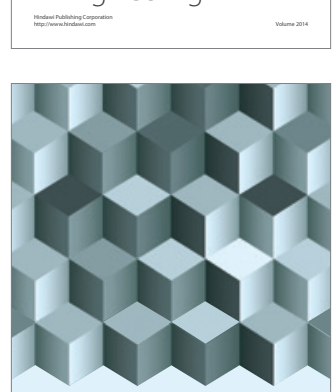

Journal of

Function Spaces
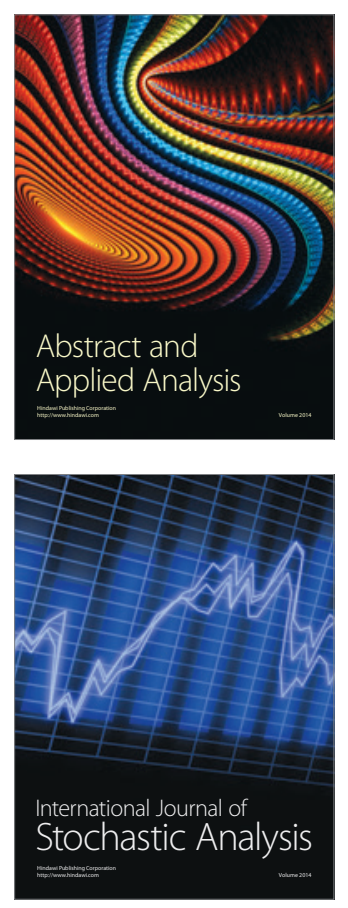

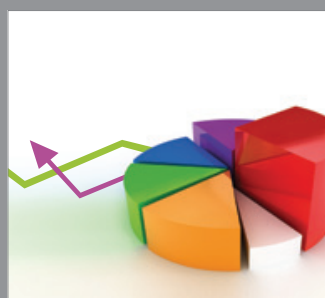

ournal of

Probability and Statistics

Promensencen
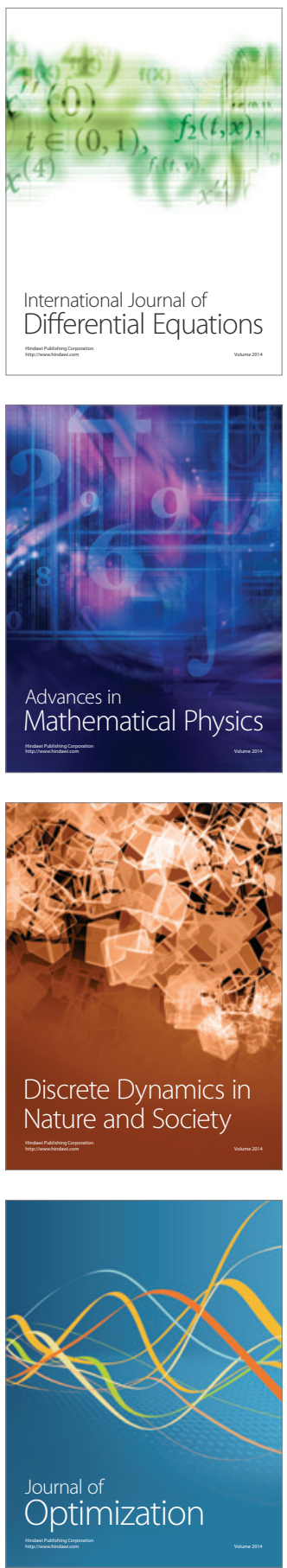